\title{
Nutritional Disorders and Food Development: Problems and Potential Solutions
}

\section{Ion C. Baianu*}

AFC-NMR \& NIR Microspectroscopy Facility, College of ACES, FSHN \& NPRE Departments, University of Illinois at Urbana, Urbana, IL 61801, USA

Nutrition-related disorders are increasingly wide-spread in the United States of America and the European Union. There are major concerns about the recent rise in obesity-related diseases, such as type II diabetes, as well as heart diseases, especially coronary artery disease (CAD) and atherosclerosis. The latter is the number one cause of deaths in the Western World.

Potential solutions to such major nutrition-related, major problems of modern society require a rational approach to finding adequate solutions that are both effective and practical to achieve a long term resolution. A rational approach involves multiple levels of determined action ranging from regulatory to food development and marketing of healthier foods, as well as improved food consumer education and awareness of how to judge the quality of foods.

In this concise article the focus is on rational solutions to solve such major health problems related to nutrition disorders that are based on a complex systems analysis (CSA), combined with novel food development strategies that would make available in the market healthier foods that can both prevent and treat obesity-related diseases such as type II diabetes. Such healthy foods might also be beneficial for the prevention and amelioration of heart disease although insufficient data is available to definitively prove such an important claim. Novel research findings and complex models in food chemistry can greatly assist in the development of new foods designed to address the specific problems of obese populations, and/or diabetic patients who would not have to depend any longer upon taking pills daily just to maintain their existing status. Clearly, the complete solution must also include progressively increasing exercise and fitness programs tailored to address the individual needs and physical capabilities of each diabetic patients, combined with an adequate amount of medical supervision, and also followed up by adequately trained nurses.

As an example, let us consider first the interesting fact that there are several trials of a special type of a partially soluble fiber (called poly-glucomnnans by food chemists, and also by biochemists/organic chemists) which is commonly used in foods in both Japan and Korea. Available quite inexpensively, and in large quantities, in most oriental stores in the U.S.A as well, this food component which is generally regarded as safe can be readily incorporated into bread, pancakes, cakes, soups, gels, surimi-analogs, and so on. It does not need to be ingested as 1-gram pill form as expensively marketed by US trial programs for lowering blood sugar levels, thus helping diabetes patients. The basic ingredient is extracted from, and marketed as, a flour of potato-like tubers of the konjac (Amorphophalus $\mathrm{k}$ ) plant, improperly called Korean yam. It has had many uses in the Japanese and Korean food industries for the last two thousand years and is generally regarded as safe (GRAS) for use in foods. A more detailed study and discussion of the food uses of the konjac, fiber-like substance has been published [1] in 1992, also summarizing in English the extensive literature on konjac glucomannans, previously available only in Japanese. Additional research results obtained in the USA with konjac poly-glucomannans were presented subsequently at an American Chemical Society meeting [2], and included also in a recent review this year [3]. It has taken, however, more than a decade to move from the research laboratory stage and scientific presentation of results to trials with expensive preparations that can be however obtained as inexpensive ingredients in large quantities in the US markets. However, there are yet no foods based on the konjac flour ingredient in the US supermarkets that could help a large and increasing population of diabetic patients and overweight Americans. The remaining question is: how long will take to bring such konjac-based, healthy foods into the US food supply?

This is only one example of how novel approaches that employ food physical chemistry results and complex systems analysis may rapidly benefit the US food consumer in the near future. Obviously, there are many others, but this is the first to be brought to the attention of both the American consumer and US food companies in an attempt to develop rational solutions to nutrition-related disorders.

Other examples of using novel physical chemistry methodology and complex systems analysis in addressing other health problems were recently presented in references [4-11].

\section{References}

1. Ozu EM, Baianu IC, Wei LS (1992) Physical and Chemical Properties of Glucommannan Gels and Related Polysaccharides. Physical Chemistry of food Processes 2: 518-541.

2. Baianu IC, Ozu EM (2002) Gelling Mechanisms of Glucomannan Polysaccharides and Their Interactions with Proteins. ACS Symposium Ser 834: 298-305.

3. Baianu IC, Prisecaru V (2011) NMR, NIR and Infrared Spectroscopy of Carbohydrate-Protein Interactions and glycoproteins. ACS Symposium Ser 1077: 337-352.

4. Baianu IC, Costescu D, You T, Lozano PR, Hofmann NE, et al. (2004) Near Infrared / Fluorescence Microspectroscopy, Infrared Chemical Imaging and High-Resolution NMR Analysis of Soybean Seeds, Somatic Embryos and Single Cancer Cells. AOCS Press 241-273.

5. Baianu IC (2012) Clinical Trials in Cancer and Pharmacogenomics: A Critical Evaluation. J Clinical Trials 1: 001-039.

6. Baianu IC (2011) Translational Oncogenomics and Human Cancer Interactomics: Advanced Techniques and Complex System Dynamic Approaches. Bioinformatics - Trends and Methodologies 473-510.

7. Jonsson PF, Bates PA (2006) Global topological features of cancer proteins in the human Interactome. Bioinformatics 22: 2291-2297.

8. Jonsson PF, Cavanna T, Zicha D, Bates PA (2006) Cluster analysis of networks generated through homology: automatic identification of important protein communities involved in cancer metastasis. BMC Bioinformatics 7: 2.

9. Prisecaru VI, Baianu IC (2004) Cell Cycling Models of Carcinogenesis: A Complex Systems Analysis. Q bio MN 1-22.

*Corresponding author: Ion C. Baianu, AFC-NMR \& NIR Microspectroscopy Facility, College of ACES, FSHN \& NPRE Departments, University of Illinois at Urbana, Urbana, IL 61801, USA, E-mail: ibaianu@illinois.edu

Received June 21, 2012; Accepted June 23, 2012; Published June 25, 2012

Citation: Baianu IC (2012) Nutritional Disorders and Food Development: Problems and Potential Solutions. J Nutr Disorders Ther 2:e103. doi:10.4172/2161 $0509.1000 \mathrm{e} 103$

Copyright: (C) 2012 Baianu IC. This is an open-access article distributed under the terms of the Creative Commons Attribution License, which permits unrestricted use, distribution, and reproduction in any medium, provided the original author and source are credited. 
Citation: Baianu IC (2012) Nutritional Disorders and Food Development: Problems and Potential Solutions. J Nutr Disorders Ther 2:e103. doi:10.4172/2161-0509.1000e103

Page 2 of 2

10. Sørlie T, Perou CM, Tibshirani R, Aas T, Geisler S, et al. (2001) Gene expression patterns of breast carcinomas distinguish tumor subclasses with clinical implications. Proc Natl Acad Sci U S A 98: 10869-10874.
11. Rigler R, Widengren J (1990) Ultrasensitive detection of single molecules by fluorescence correlation spectroscopy. BioScience 180-184.

12. Plass C (2002) Cancer Epigenomics. Human Mol Genet 11: 2479-2488. 